\title{
P2X7R antagonist protects against renal injury in mice with adriamycin nephropathy
}

\author{
YANJI ZHU, MIN LIU, WENLONG XUN, KELIANG LI and XIANGJI NIU \\ Department of Pediatrics, People's Hospital of Rizhao Affiliated to Jining Medical University, \\ Rizhao, Shandong 276800, P.R. China
}

Received June 1, 2020; Accepted November 15, 2021

DOI: $10.3892 /$ etm.2021.11084

\begin{abstract}
Activation of the purinergic P2X7 receptor (P2X7R) has been associated with the development of experimental nephritis. Therefore, the current study aimed to explore the mechanism of P2X7R in renal injured mice with adriamycin (ADR) nephropathy. The protective effect of a P2X7R antagonist on the kidneys of mice with ADR nephropathy was also evaluated. Nephropathy was induced by a single intravenous injection of ADR $(10.5 \mathrm{mg} / \mathrm{kg})$. A total of $6 \mathrm{~h}$ before the model was established, the P2X7R antagonist A438079 (100, 200 and $300 \mu \mathrm{mol} / \mathrm{kg}$ ) was injected into the mice, which was subsequently administered daily for 1 week by intraperitoneal injection. Subsequently, all mice were sacrificed, after which blood, 24 h-urine and the kidneys were collected. The levels of albumin (ALB) and total cholesterol (TC) in the serum, along with urine protein content at $24 \mathrm{~h}$ were determined using an automatic biochemical analyzer. The levels of IL-1 $\beta$ and IL-18 were additionally detected in the renal tissues by ELISA. Moreover, the expression of P2X7R, oxidized (ox)-low density lipoprotein (LDL), C-X-C motif chemokine ligand 16 (CXCL16), Bax, caspase-3 and NLRP3 in renal tissues was detected by immunohistochemistry. Apoptosis in the renal tissues was observed using the TUNEL assay. The results demonstrated that compared with the control group, decreased weight, increased proteinuria, decreased serum ALB and increased serum TC was observed in the ADR group. The expression of IL-1 $\beta$, IL-18, P2X7R, ox-LDL, CXCL16, Bax, caspase-3 and NLRP3, as well as cellular apoptosis in the renal tissues of the ADR group, was significantly increased in the ADR group compared with the control. However, compared with the ADR group, the changes in all indices in the ADR + A438079 groups were attenuated. Overall, P2X7R, ox-LDL
\end{abstract}

Correspondence to: Dr Xiangji Niu, Department of Pediatrics, People's Hospital of Rizhao Affiliated to Jining Medical University, 126 Tai'an Road, Rizhao, Shandong 276800, P.R. China

E-mail: niuxiangji005@126.com

Key words: adriamycin, nephropathy, $\mathrm{P} 2 \mathrm{X} 7$ receptor, oxidized-low density lipoprotein, C-X-C motif chemokine ligand 16, Bax, caspase-3, NLRP3 and CXCL16 may be associated with ADR nephropathy, while inhibition of $\mathrm{P} 2 \mathrm{X} 7 \mathrm{R}$ may reduce the expression of ox-LDL by downregulating the CXCL16 pathway to alleviate kidney injury in mice with ADR nephropathy. Furthermore, activated P2X7R may promote the release of inflammatory cytokines IL-1 $\beta$ and IL-18 through the downstream P2X7R/NLRP3 pathway and upregulate the expression of Bax and caspase- 3 to promote apoptosis, which participates in the process of ADR nephropathy. Inhibiting P2X7R may also reduce the release of IL-1 $\beta$ and IL-18 by downregulating the P2X7R/NLRP3 pathway, downregulating the expression of Bax and caspase-3, and reducing apoptosis, thereby alleviating kidney injury in mice with ADR nephropathy.

\section{Introduction}

Primary nephrotic syndrome (PNS) is one of the most common kidney diseases in children. It is induced by various causes, including weak resistance and weakened immune function, leading to the increased permeability of the glomerular filtration membrane and the loss of a large amount of protein in the urine, consequently leading to a clinical syndrome with a series of pathophysiological changes (1). At present, the pathogenesis of PNS remains unknown. Adriamycin (ADR) nephropathy, which is very similar to early stage minimal change disease (MCD) and late stage focal segmental glomerulosclerosis, is a classic animal model of nephrotic syndrome (NS) (2-5).

The $\mathrm{P} 2 \mathrm{X} 7$ receptor $(\mathrm{P} 2 \mathrm{X} 7 \mathrm{R})$, which belongs to the $\mathrm{P} 2 \mathrm{X}$ family, is an ATP-gated ion channel that is involved in the development of numerous diseases, such as HIV infection (6). Compared with other family members, P2X7R has a specific structure, which has attracted marked attention (7). P2X7R is involved in the inflammatory response through numerous signaling pathways, promoting cellular injury and apoptosis, thus leading to tissue damage (6). At present, accumulating evidence from various animal models has shown that P2X7R participates in the onset and development of kidney disease through the P2X7R/NLRP3 pathway, which could lead to the downstream release of IL-1 $\beta$ and IL-18 to play a role in inflammation (8-11). P2X7R promotes apoptosis in a variety of ways. Previous studies on several kidney diseases have revealed that P2X7R could lead to mesangial cell and podocyte apoptosis, which may participate in the pathogenesis of diseases $(12,13)$. Furthermore, P2X7R is important for lipid storage and 
metabolism in the body (14). Oxidized (ox)-low density lipoprotein (LDL) has been found to upregulate the expression of $\mathrm{P} 2 \mathrm{X} 7 \mathrm{R}$ in atherosclerosis (15). In addition, ox-LDL is involved in the onset and development of ADR nephropathy (16), and it has been confirmed that the expression of P2X7R and ox-LDL is increased in the glomeruli of children with PNS (Zhu et al, unpublished data). However, whether P2X7R is involved in the onset and development of ADR nephropathy has not been reported locally or abroad, to the best of our knowledge.

In the present study, a mouse model of ADR nephropathy was established to explore the pathogenesis of PNS, to investigate the role of P2X7R in ADR-induced nephropathy, and to determine whether P2X7R inhibition could ameliorate renal injury in mice with ADR nephropathy.

\section{Materials and methods}

Experimental animals. Male BABL/c mice (age, 5 weeks; $\mathrm{n}=46$ ) with an average body weight of $17.96 \mathrm{~g}$ (Vital River Laboratory Animal Technology Co. Ltd.) were kept under standard conditions (constant temperature $21 \pm 2^{\circ} \mathrm{C}$, humidity $60 \pm 10 \%$, light/dark cycle $12 \mathrm{~h}$ ) and received free water and food and standard pellet chow. All animal procedures were performed according to the guidelines for the care and use of laboratory animals approved by Shandong Provincial Hospital. Mice were anesthetized by an intraperitoneal injection of $100 \mathrm{mg} / \mathrm{kg}$ sodium pentobarbital. The use of large-dose injections results in the inhibited breathing of mice. Death was confirmed when mice did not respond to stimuli, as their hind limbs were clamped with the hemostatic forceps.

Sample collection. Mice were randomly divided into the following groups: Normal control group (NC group; $n=5$ ), ADR nephropathy group (ADR group; n=5), ADR + A438079 $(100 \mu \mathrm{mol} / \mathrm{kg}$; Merck KGaA) group (ADR + A100 group; $\mathrm{n}=5)$, ADR + A438079 $(200 \mu \mathrm{mol} / \mathrm{kg})$ group (ADR + A200 group; $\mathrm{n}=5), \mathrm{ADR}+\mathrm{A} 438079(300 \mu \mathrm{mol} / \mathrm{kg})$ group (ADR + A300 group, $\mathrm{n}=5)$ and A438079 (300 $\mu \mathrm{mol} / \mathrm{kg})$ group (A300 group; $\mathrm{n}=5$ ). The ADR group was induced by a single, slow intravenous injection of ADR $(10.5 \mathrm{mg} / \mathrm{kg}$ body weight, diluted in $0.9 \%$ saline) into the tail vein. After 1 week, mice with massive proteinuria (24-h urinary protein ratio $\geq 50 \mathrm{mg} / \mathrm{kg}$ ) were considered to have ADR nephropathy. The other groups without ADR received the same dose of saline via the tail vein. The P2X7R antagonist A438079 (100, 200 and $300 \mu \mathrm{mol} / \mathrm{kg})$ was injected intraperitoneally $6 \mathrm{~h}$ before establishing the models, after which A438079 (100, 200 and $300 \mu \mathrm{mol} / \mathrm{kg})$ was administered every day for 1 week.

After 1 week, all mice were individually placed in metabolic cages for 24-h urine collection. Following urine collection, all mice were anesthetized and euthanized by intraperitoneal injection of $100 \mathrm{mg} / \mathrm{kg}$ sodium pentobarbital. Blood was collected from the heart, and the kidneys were harvested. All experiments were performed with the approval of the Animal Ethics Committee of Shandong Provincial Hospital (Jinan, China; approval no. 2020-107).

Urinary protein and blood sample analysis. The 24-h urinary protein ratio was detected using the Coomassie brilliant blue method. Serum albumin (ALB) and total cholesterol (TC) were evaluated using an Automatic Biochemical analyzer (AU5400; Olympus Corporation). All specimens were processed and analyzed according to the manufacturer's protocol.

ELISA. Sandwich ELISA was used to detect the levels of IL-1 $\beta$ (cat. 70-EK201B/3-96, Multi sciences, Wuhan, China) and IL-18 (cat. 70-EK218-96, Multi sciences, Wuhan, China) in kidney tissue according to the manufacturer's protocol (Multi Sciences Biotech, Co., Ltd.). Briefly, a section of fresh kidney was collected, placed in PBS with $0.05 \%$ Tween-20 and mixed using ultrasound for $100 \mathrm{sec}$. Subsequently, the kidney supernatant was harvested. Standard proteins and samples were subsequently diluted with standard diluent buffer supplied in the aforementioned kit, after which $100 \mu \mathrm{l}$ of standards, controls and diluted samples was added to the appropriate microtiter 96-wells. The wells were covered and incubated for $90 \mathrm{~min}$ at $37^{\circ} \mathrm{C}$ in an incubator. Biotin-conjugated detection antibody $(100 \mu \mathrm{l})$ was added into each well after washing with PBS, incubated for $1 \mathrm{~h}$ at $37^{\circ} \mathrm{C}$ and washed again with PBS. Anti-rabbit IgG-HRP $(100 \mu \mathrm{l})$ was then added to each well, after which the wells were covered and incubated for $30 \mathrm{~min}$ at $37^{\circ} \mathrm{C}$. Following another PBS wash step, stabilized chromogen $(90 \mu \mathrm{l})$ was added to each well and incubated for $15 \mathrm{~min}$ at $37^{\circ} \mathrm{C}$ in the dark. Finally, stop solution was added to each well, and the absorbance of each well at $450 \mathrm{~nm}$ was recorded by a microtiter plate reader. A smooth standard curve was constructed according to standard protein optical density values. Unknown sample protein concentrations were derived from this standard curve.

Immunohistochemical assay. The right kidney was fixed at $4^{\circ} \mathrm{C}$ for $24 \mathrm{~h}$ in $10 \%$ formaldehyde immediately after the mice were sacrificed, after which it was dehydrated in graded alcohol and then embedded in paraffin. Paraffin sections $(5 \mu \mathrm{m})$ were deparaffnized in an environmentally-safe cleaning agent, such as xylene, rehydrated in graded alcohol and then washed in PBS (pH 7.4). Antigen retrieval was performed by boiling the tissue sections in water for $15 \mathrm{~min}$ in $0.01 \mathrm{~mol} / 1$ sodium citrate buffer ( $\mathrm{pH} 6.0$ ) at $100^{\circ} \mathrm{C}$ and then cooling at $25^{\circ} \mathrm{C}$ for $2 \mathrm{~h}$. Tissue sections were treated with $3 \% \mathrm{H}_{2} \mathrm{O}_{2}$ for $30 \mathrm{~min}$ at $37^{\circ} \mathrm{C}$ to quench endogenous peroxide activity. After blocking the sections with $10 \%$ goat serum (Beijing Solarbio Science \& Technology Co., Ltd.) for $1 \mathrm{~h}$ at $37^{\circ} \mathrm{C}$, the sections were incubated with rabbit anti-mouse P2X7R antibody (pAb; 1:300; cat. no. ab109054; Abcam), C-X-C motif chemokine ligand 16 (CXCL16; 1:100; cat. no. bs-1441R; BIOSS), ox-LDL (1:100; cat. no. bsm-1698M; BIOSS), Bax (1:200; cat. no. bsm-52316R; BIOSS), caspase-3 (1:200; cat. no. bsm-33277M; BIOSS) and NLRP3 (1:200; cat. no. ab270449; Abcam) at $4^{\circ} \mathrm{C}$ overnight, followed by incubation with HRP-conjugated secondary goat anti-rabbit (1:500; cat. no. ab6721; Abcam)/mouse (1:500; cat. no. ab6789; Abcam) antibody at $37^{\circ} \mathrm{C}$ for $30 \mathrm{~min}$. Sections were developed with DAB reagent, after which the nuclei were counterstained with Hematoxylin for $1 \mathrm{~min}$ at room temperature. The primary antibody was substituted for PBS as a negative control, while the positive control was verified by confirming positively-stained tissue specimens. Images were captured using the white light of an ECLIPSE Ti scanning microscope (Nikon Corporation) and analyzed by ImageJ software (version, 6.0; National Institutes of Health) to calculate \%Area. 

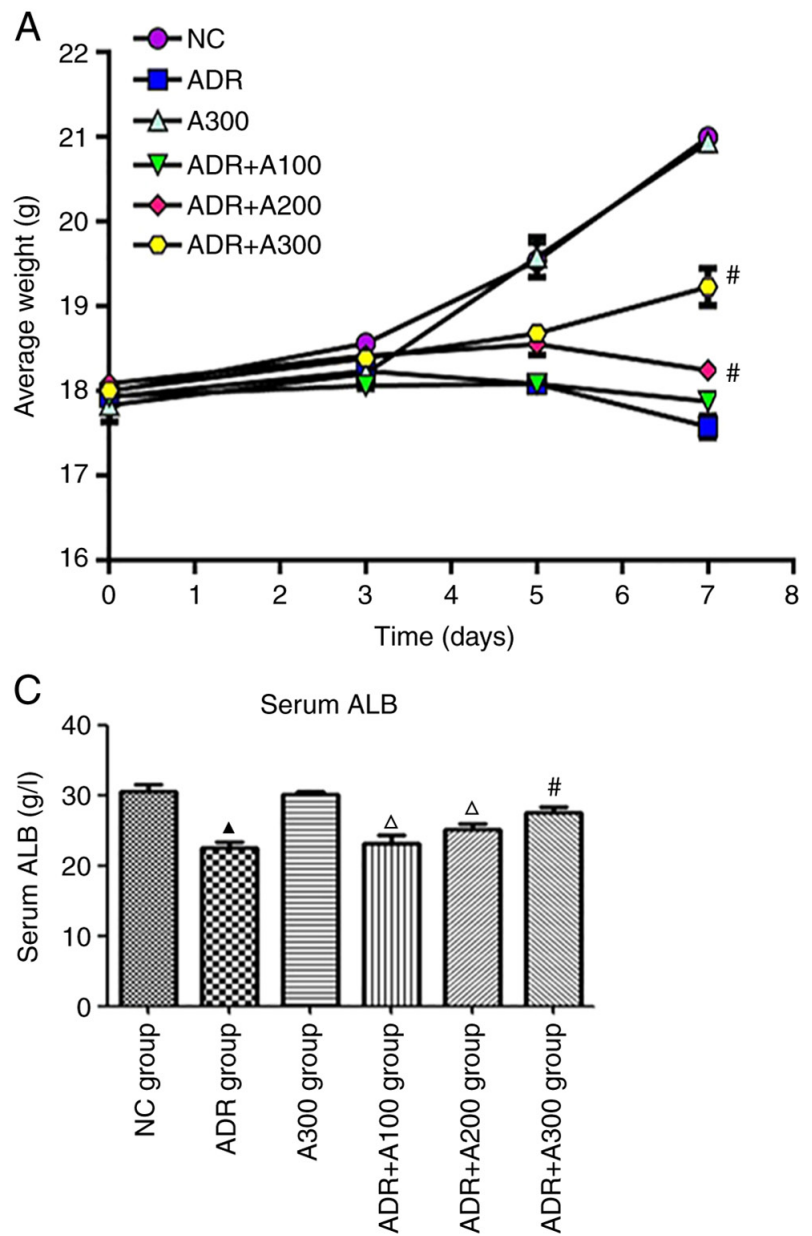

B

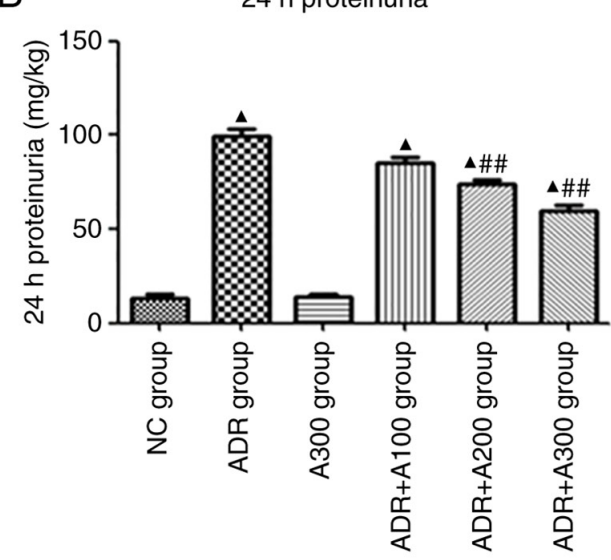

D

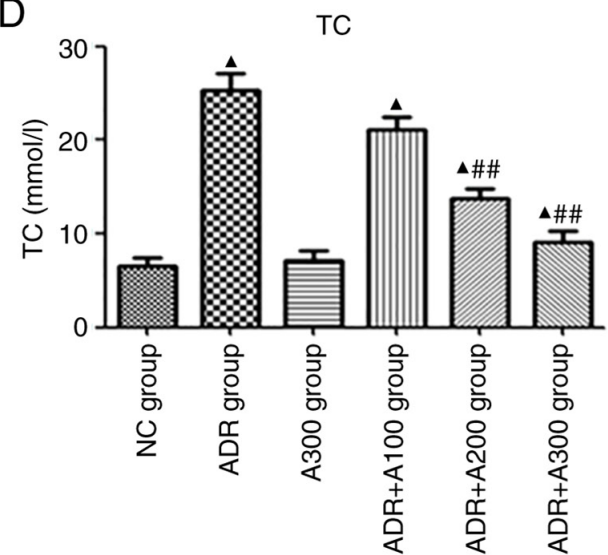

Figure 1. Weight, 24-h proteinuria, serum ALB and TC changes in the different treatment groups. (A) Weight changes of mice in the different treatment groups was assessed over time. (B) 24 -h proteinuria, (C) serum ALB and (D) TC levels in the different treatment groups. ${ }^{\Delta} \mathrm{P}<0.05$ and ${ }^{\wedge} \mathrm{P}<0.01$ vs. NC group; ${ }^{*} \mathrm{P}<0.05$ and ${ }^{\# \#}$ P $<0.01$ vs. ADR group. ADR, adriamycin; ALB, albumin; A100/200/300, A438079 100/200/300 $\mu \mathrm{mol} / \mathrm{kg}$; TC, total cholesterol; NC, negative control.

TUNEL assay. The right kidney was fixed at $4^{\circ} \mathrm{C}$ for $24 \mathrm{~h}$ in $10 \%$ formaldehyde immediately after the mice were sacrificed, after which it was dehydrated in graded alcohol and then embedded in paraffin. Paraffin sections $(5 \mu \mathrm{m})$ were deparaffnized in an environmentally-safe cleaning agent, such as xylene, rehydrated in graded alcohol and then washed in PBS ( $\mathrm{pH}$ 7.4). Antigen retrieval was performed by boiling the tissue sections in water for $15 \mathrm{~min}$ in $0.01 \mathrm{~mol} / 1$ sodium citrate buffer $(\mathrm{pH} 6.0)$ at $100^{\circ} \mathrm{C}$ and then cooling at $25^{\circ} \mathrm{C}$ for $2 \mathrm{~h}$. Tissue sections were treated with $3 \% \mathrm{H}_{2} \mathrm{O}_{2}$ for $10 \mathrm{~min}$ at $37^{\circ} \mathrm{C}$ to quench endogenous peroxide activity. Then added TdT enzyme reaction solution to the tissue, and reacted for $1 \mathrm{~h}$ at $37^{\circ} \mathrm{C}$ in the dark. Then add 1 Streptavidin-HRP working solution, and react for $30 \mathrm{~min}$ in the dark at $37^{\circ} \mathrm{C}$. Sections were developed with DAB reagent, after which the nuclei were counterstained with Hematoxylin for $1 \mathrm{~min}$ at room temperature. Images were captured using the white light of an ECLIPSE Ti scanning microscope (Nikon Corporation) and analyzed by ImageJ software (version 6.0; National Institutes of Health) to calculate the dark brown precipitated cells.

Statistical analysis. Statistical analysis was performed using SPSS 19.0 (IBM Corp.), and the data were expressed as the mean $\pm \mathrm{SD}$. The means between multiple groups were compared using one-way ANOVA. For the comparison of two groups, an independent sample t-test was used. $\mathrm{P}<0.05$ was considered to indicate a statistically significant difference.

\section{Results}

Effect of A438079 on weight, urinary protein, serum ALB, and $T C$. As revealed in Fig. 1, compared with the NC group, the weight of mice in the ADR group gradually decreased. Additionally, compared with the ADR group, weight loss was significantly reduced in both the ADR + A200 and ADR + A300 groups, while there was no significant difference in the ADR + A100 group. The ADR group developed significant proteinuria, hypoalbuminemia and hyperlipidemia, while in the ADR + A438079 groups, the majority of changes were alleviated to varying degrees depending on the concentration of A438079. The level of 24 h-proteinuria in the ADR and ADR + A438079 groups was significantly higher compared with the NC group (Fig. 1B; $\mathrm{P}<0.01$ ), and the level of 24 h-proteinuria in the ADR + A438079 200 and $300 \mu \mathrm{mol} / \mathrm{kg}$ groups was significantly lower than that in the ADR group (Fig. 1B; $\mathrm{P}<0.01$ ). However, no statistically significant difference was observed in the ADR + A100 group compared with the ADR group (Fig. 1B; P>0.05). Serum ALB levels in the ADR and ADR + A438079 100 and $200 \mu \mathrm{mol} / \mathrm{kg}$ groups were significantly lower than those in the NC group 

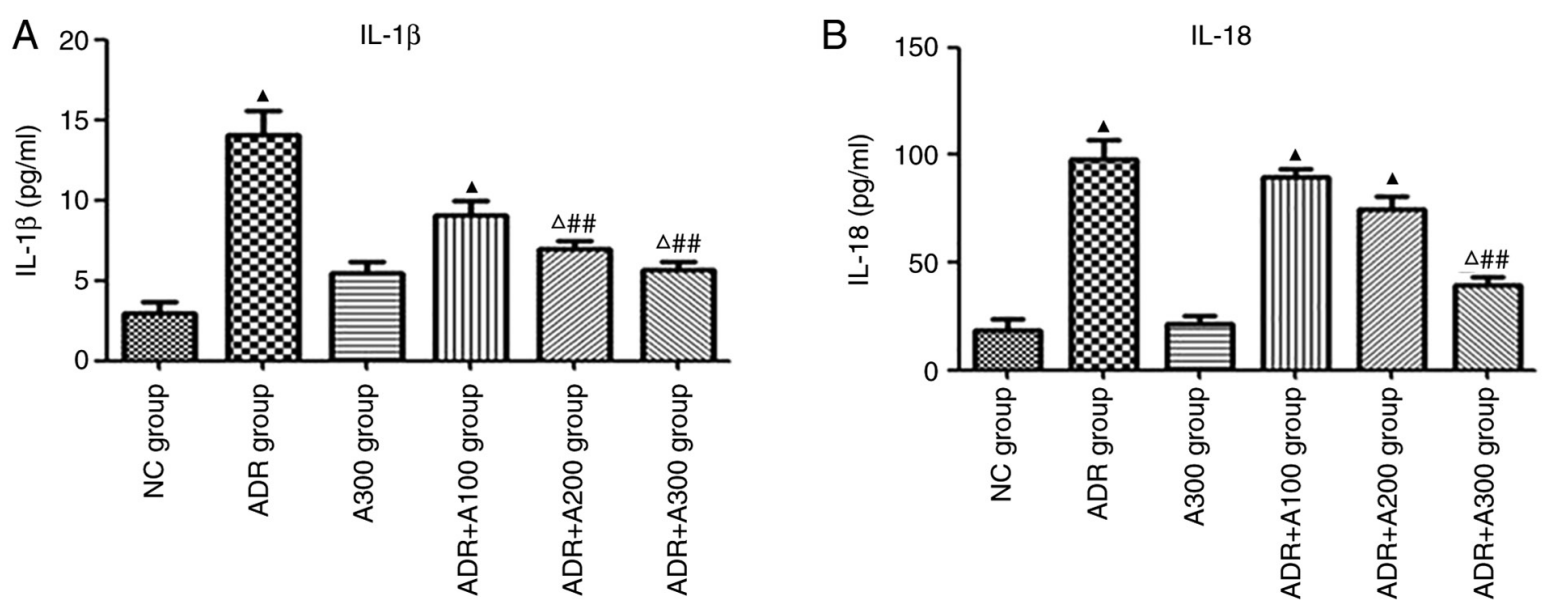

Figure 2. Levels of IL-1 $\beta$ and IL-18 in murine renal tissues. The levels of (A) IL-1 $\beta$ and (B) IL-18 were evaluated in the renal tissues of mice in each treatment group. ${ }^{\Delta} \mathrm{P}<0.05$ and ${ }^{\Delta} \mathrm{P}<0.01$ vs. NC group; ${ }^{\# \#} \mathrm{P}<0.01$ vs. ADR group. ADR, adriamycin; A100/200/300, A438079 100/200/300 $\mu$ mol $/ \mathrm{kg} ; \mathrm{NC}$, negative control.

(Fig. 1C; $\mathrm{P}<0.01$ or $\mathrm{P}<0.05$ ). Furthermore, compared with the ADR group, changes in serum ALB were only reduced in the $\mathrm{ADR}+\mathrm{A} 300$ group (Fig. 1B; $\mathrm{P}<0.05$ ). The levels of TC in the ADR and ADR + A438079 100 and $200 \mu \mathrm{mol} / \mathrm{kg}$ groups were significantly higher than those in the NC group (Fig. 1D; $\mathrm{P}<0.01)$. However, TC levels in the ADR + A438079 200 and $300 \mu \mathrm{mol} / \mathrm{kg}$ groups were significantly lower than those in the ADR group (Fig. 1D; $\mathrm{P}<0.01)$.

Effect of $A 438079$ on IL-1 $\beta$ and IL-18 expression in renal tissues. IL-1 $\beta$ and IL-18 expression was evaluated in the kidneys of mice from each treatment group by ELISA. The expression of IL-1 $\beta$ and IL-18 in the ADR group was significantly higher than that in the NC group (Fig. 2A and B; $\mathrm{P}<0.01)$. Compared with the ADR group, IL-1 $\beta$ levels in the $\mathrm{ADR}+\mathrm{A} 438079200$ and $300 \mu \mathrm{mol} / \mathrm{kg}$ groups were alleviated (Fig. 2A; P<0.01). However, IL-18 levels were only significantly reduced in the ADR + A300 group (Fig. 2B; $\mathrm{P}<0.01)$.

Effect of $A 438079$ on the expression of $P 2 X 7 R$, ox-LDL, CXCL16, Bax, caspase-3, and NLRP3 in the glomeruli. To investigate the expression of P2X7R, ox-LDL, CXCL16, Bax, caspase-3 and NLRP3 in the glomeruli of different treatment groups, immunohistochemical analysis was performed. The expression of P2X7R, ox-LDL, CXCL16, Bax, caspase-3 and NLRP3 in the glomeruli of the ADR group was significantly increased (Fig. 3A-L; P<0.01) compared with that of the NC group. Compared with the ADR group, the expression of these genes in the ADR + A438079 200 and $300 \mu \mathrm{mol} / \mathrm{kg}$ groups were significantly reduced (Fig. $3 \mathrm{~A}-\mathrm{L} ; \mathrm{P}<0.05$ or $\mathrm{P}<0.01$ ). However, there was no statistically significant difference observed in the ADR + A100 group compared with the ADR group (Fig. 3A-L; P>0.05).

Effect of A438079 on apoptosis in the glomeruli of mice. The apoptosis of glomeruli in the ADR group was significantly increased compared with that in the NC group (Fig. 4; $\mathrm{P}<0.01$ ). Furthermore, compared with the ADR group, the apoptosis of glomeruli in the ADR + A438079 100, 200 and $300 \mu \mathrm{mol} / \mathrm{kg}$ groups was significantly decreased (Fig. 4; $\mathrm{P}<0.01$ ).

\section{Discussion}

PNS is a common kidney disease in children, with glucocorticoids applied as the preferred clinical treatment for NS. The most common pathological type of PNS is MCD, and the majority of children with PNS are sensitive to steroid therapy, thus exhibiting a favorable prognosis. However, certain children with steroid-dependent or steroid-resistant NS may gradually progress to focal segmental glomerular sclerosis (FSGS) and eventually to end-stage renal disease (ESRD) (17). Therefore, it is important to identify the target of early kidney damage and to find an effective therapy for the occurrence and development of PNS.

ADR nephropathy in mice, which simulates the pathological characteristics of human NS with the early pathological manifestation of MCD and the late pathological manifestation of FSGS, is a classic animal experimental model of NS $(4,5)$. In the present study, BALB/c mice were sensitive to ADR and exhibited similarities to human NS with MCD and FSGS, such as high urine protein. In addition, it is more convenient and economical to use mice to conduct research, as they exhibit a high reproductive ability and are easy to raise (5). BALB/c mice were selected to establish the model of ADR nephropathy. Mice were injected with ADR $(10.5 \mathrm{mg} / \mathrm{kg})$ via the tail vein. After 1 week, the mice displayed massive proteinuria, hypoalbuminemia and hyperlipidemia. Furthermore, previous pathological analysis of renal tissues carried out in our laboratory revealed the distinct proliferation of mesangial cells, and a marked expansion of the mesangial matrix (16). The results from electron microscopy suggested that the glomerular basement membrane was pervasively thickened, and the foot processes were widely fused (16). All changes gradually became markedly with time. Collectively, these results suggested that the ADR nephropathy model was successfully established (16). Therefore, BALB/c mice were selected as the ADR nephropathy animal model in the present study.

$\mathrm{P} 2 \mathrm{X} 7$ receptor $(\mathrm{P} 2 \mathrm{X} 7 \mathrm{R})$ is a ligand-gated ion channel that is a member of the $\mathrm{P} 2 \mathrm{X}$ receptor family. Although $\mathrm{P} 2 \mathrm{X} 7 \mathrm{R}$ is similar to other $\mathrm{P} 2 \mathrm{X}$ receptors, it has a special structure with a longer C-terminal (18). Previous studies have shown that P2X7R was involved in various kidney diseases, including 


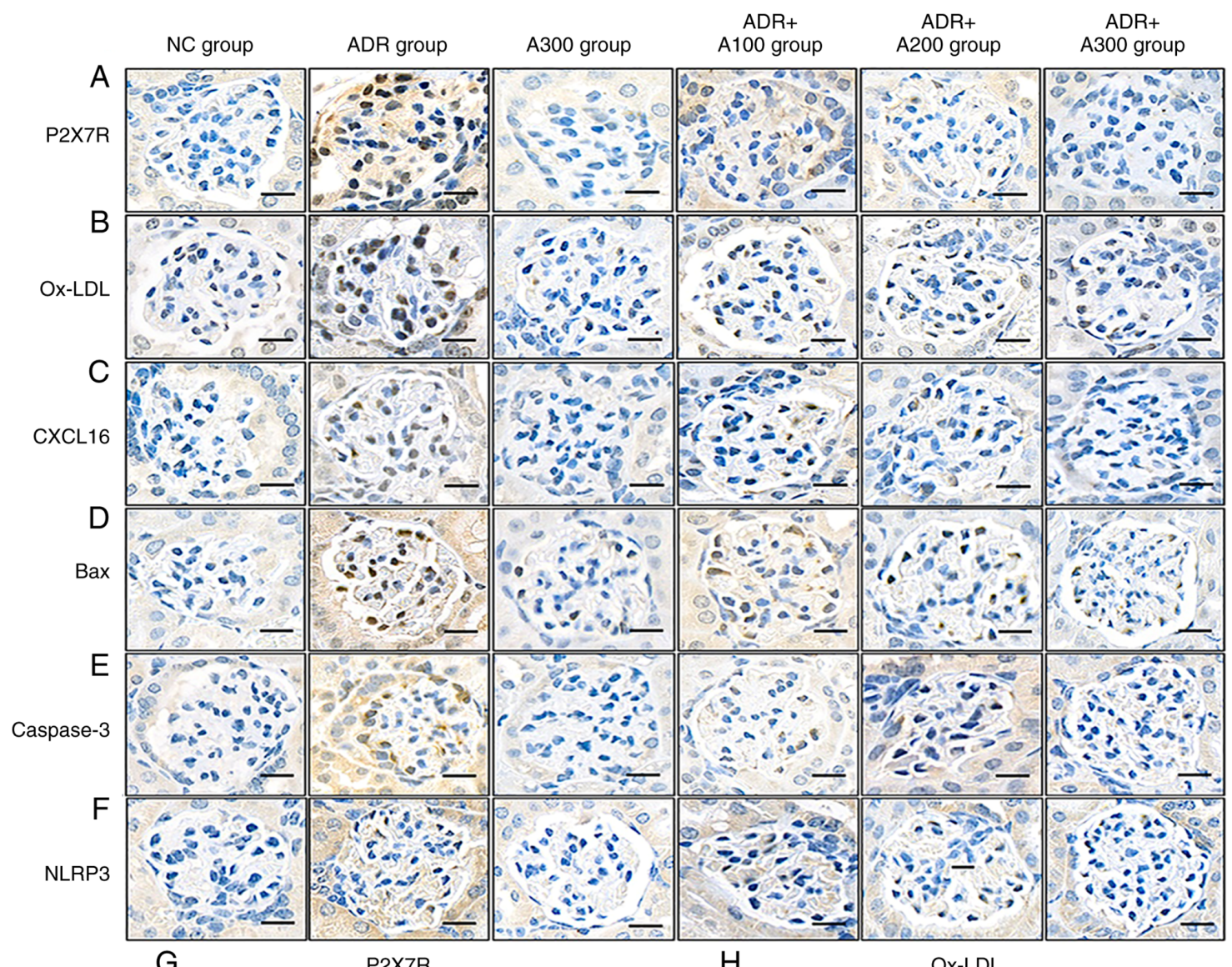

G

P2X7R
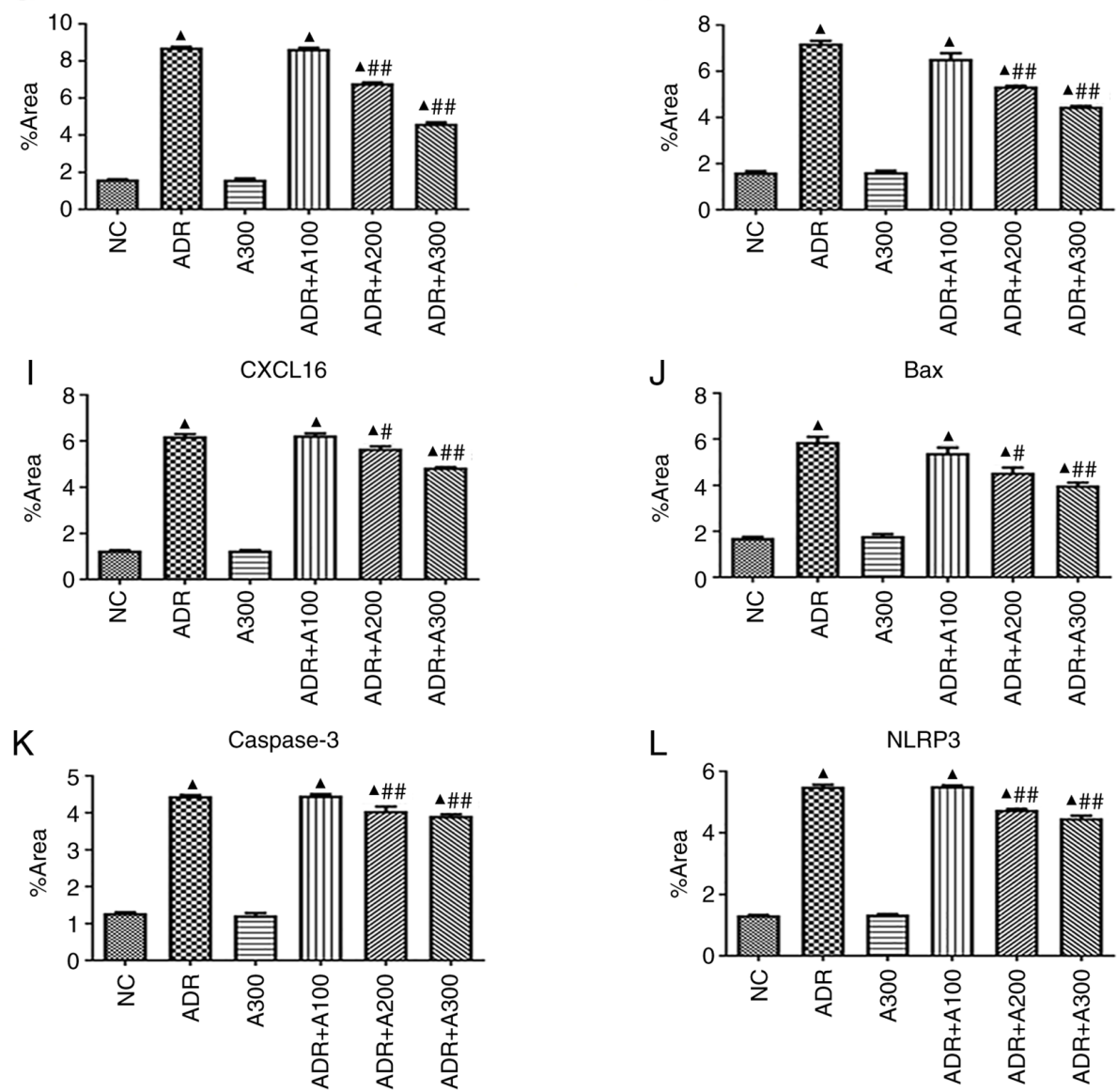

Figure 3. Effect of A438079 on the expression of P2X7R, ox-LDL, CXCL16, Bax, caspase-3 and NLRP3 in the glomeruli. Expression of (A and G) P2X7R, (B and H) ox-LDL, (C and I) CXCL16, (D and J) Bax, (E and K) caspase-3 and (F and L) NLRP3 in glomeruli with different groups. ${ }^{\mathbf{}} \mathrm{P}<0.01 \mathrm{vs}$. NC group; ${ }^{P} \mathrm{P}<0.05$ and ${ }^{\# \#} \mathrm{P}<0.01$ vs. ADR group. ADR, adriamycin; A100/200/300, A438079 100/200/300 $\mu \mathrm{mol} / \mathrm{kg}$; CXCL16, C-X-C motif chemokine ligand 16; $\mathrm{NC}$, negative control; ox-LDL, oxidized low density lipoprotein. 

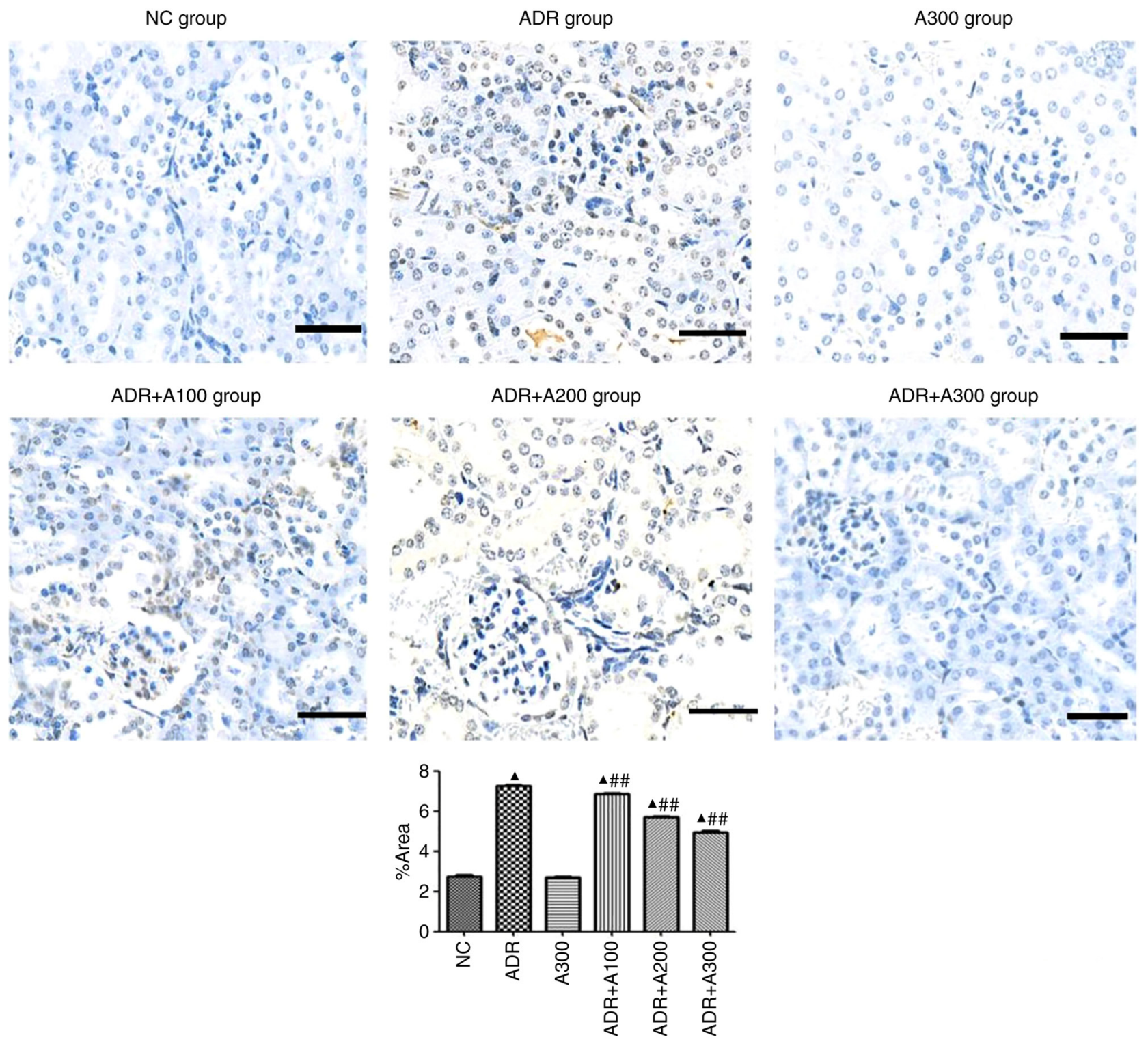

Figure 4. Expression of apoptosis in the glomeruli of the different groups determined using a TUNEL assay. ${ }^{\mathbf{}} \mathrm{P}<0.01$ vs. NC group and ${ }^{\# \#} \mathrm{P}<0.01 \mathrm{vs}$. ADR group. Scale bar, $20 \mu \mathrm{m}$. ADR, adriamycin; A100/200/300, A438079 100/200/300 $\mu \mathrm{mol} / \mathrm{kg}$; NC, negative control.

polycystic kidney disease, diabetic nephropathy, hypertension nephropathy and renal ischemia-reperfusion injury (8-11). In a diabetic nephropathy rat model, Vonend et al (19) revealed that P2X7R expression was significantly increased in the glomerular cells of diabetic nephropathy rats, and immunohistochemical staining further demonstrated that positive cells stained with brown and yellow precipitation were mainly podocytes. However, P2X7R has not been reported in regard to ADR nephropathy. In the current study, it was found that the expression of P2X7R was increased in the glomeruli of children with PNS (data not yet published), suggesting that P2X7R may be involved in the pathogenesis of NS. Thus, it was intended to confirm the result through animal models of NS. A mouse model was established by ADR and after 1 week, the following changes were observed in mice: Body weight was significantly decreased, serum ALB was decreased and TC increased. Furthermore, the expression of P2X7R in the glomeruli was also increased. Following treatment with the P2X7R antagonist A438079, the aforementioned observations in ADR-nephropathy mice were alleviated. These data suggested that P2X7R may be associated with the pathogenesis of ADR nephropathy in mice.

The animal model of ADR nephropathy is a classic model as the observed histological changes resemble those of human MCD and focal glomerulosclerosis (20). ADR induces thinning of the glomerular endothelium and podocyte effacement associated with loss of size- and charge-specific barrier to filtration of plasma proteins. These changes are seen as early as 1-2 weeks after ADR injection, and are severe by 4 weeks (21). Evidence has shown that $\mathrm{P} 2 \mathrm{X} 7 \mathrm{R}$ plays a critical role in regulating lipid storage and metabolism in vivo (14). Additionally, ox-LDL may be the potential mediator for upregulating the expression of P2X7R in atherosclerosis (15). Numerous studies have suggested that lipid deposition is present in the kidney tissue of patients with end-stage and chronic kidney diseases as well as in animal models of NS (22-25). It is broadly known that hyperlipidemia is one of the clinical manifestations of PNS in children. Studies have revealed that 
circulating LDL in hyperlipidemia, particularly ox-LDL, may be deposited in kidney forming foam cells, upregulating the expression of inflammatory factors, increasing the secretion of chemokines and the infiltration of inflammatory cells, as well as the proliferation of renal intrinsic cells, eventually leading to glomerulosclerosis $(26,27)$. Previous research has indicated that during the progression of ADR nephropathy, CXCL16 could promote the uptake of ox-LDL by podocytes, cause the accumulation of lipid in podocytes, and eventually lead to the injury of podocytes (16). In consistency, the expression of ox-LDL and CXCL16 were increased in the glomeruli of mice with ADR nephropathy in the current study, while treatment with P2X7R antagonist A438079, significantly decreased their expression. Furthermore, $\mathrm{Hu}$ et al (28) previously indicated that P2X7R may participate in lipid metabolic disorders by regulating the CXCL16 pathway. Therefore, it was hypothesized that P2X7R, ox-LDL and CXCL16 may be associated with ADR nephropathy in mice. P2X7R inhibition may therefore reduce the expression of ox-LDL by downregulating the CXCL16 pathway to alleviate kidney injury of mice with ADR nephropathy.

$\mathrm{P} 2 \mathrm{X} 7 \mathrm{R}$ is involved in the in vivo inflammatory response via a variety of signaling pathways to promote cellular injury and apoptosis, and thus induce tissue damage (6). The P2X7R/NLPR3 pathway, which promotes the release of downstream cytokines (IL-1 $\beta$ and IL-18) to induce the immune inflammatory response, is the key pathway in which P2X7R plays its pathophysiological role $(29,30)$. However, whether P2X7R/NLRP3 is also involved in the occurrence of ADR nephropathy is unknown. Therefore, in the present study, the expression of NLRP3 was detected in murine renal tissues by immunohistochemistry, and the levels of IL-1 $\beta$ and IL-18 were determined by ELISA. The results revealed that NLRP3 levels were increased in the glomeruli of ADR nephropathy mice, and the levels of IL-1 $\beta$ and IL-18 were also increased in renal tissues. While using the P2X7R antagonist, A438079, the expression of NLRP3, IL-1 $\beta$ and IL-18 was decreased, suggesting that the $\mathrm{P} 2 \mathrm{X} 7 \mathrm{R} / \mathrm{NLRP} 3$ pathway may be involved in the occurrence and development of ADR nephropathy in mice.

Turner et al (31) indicated that the mRNA expression of $\mathrm{P} 2 \mathrm{X} 7 \mathrm{R}$ was increased in the renal tissue of rats with proliferative glomerulonephritis, as well as the mRNA expression of the pro-apoptotic marker, Bax, and apoptosis in the glomeruli. In addition, caspase-3, a member of the caspase protein family, is located downstream of the caspase cascade reaction and is a key executor of the apoptotic response, playing an active role in apoptosis (32). In an animal experimental study of renal toxicity induced by cisplatin in male C57BL/6 mice, it was revealed that the expression of caspase- 3 in renal tissue was upregulated and that apoptosis was increased in the model group, while the expression of caspase-3 was significantly reduced after the preliminary administration of P2X7R antagonist A438079 (33). The expression of podocyte apoptosis in diabetic nephropathy was increased, as was the expression of the pro-apoptotic factor caspase-3 (34). In the present study, immunohistochemistry was used to detect apoptotic protein expression in the renal tissues of ADR-induced nephropathy mice. Additionally, the TUNEL method to determine the number of apoptotic cells. The expression of Bax and caspase-3 in the glomeruli of ADR nephropathy mice increased with increased apoptosis, while administration of A438079 significantly decreased the expression of Bax and caspase- 3 in the glomeruli. Furthermore, the number of apoptotic cells was significantly decreased, suggesting that P2X7R may promote apoptosis via Bax and caspase-3 to participate in the occurrence and development of ADR nephropathy in mice.

In conclusion, P2X7R, ox-LDL and CXCL16 may be associated with ADR nephropathy in mice. Inhibition of P2X7R may reduce the expression of ox-LDL by downregulating the CXCL16 pathway to alleviate kidney injury in mice with ADR nephropathy. Activated P2X7R may promote the release of inflammatory cytokines IL-1 $\beta$ and IL-18 through the downstream P2X7R/NLRP3 pathway and upregulate the expression of Bax and caspase-3 to promote apoptosis, which participates in the process of ADR nephropathy. Additionally, inhibition of P2X7R may reduce the release of IL-1 $\beta$ and IL-18 by downregulating the $\mathrm{P} 2 \mathrm{X} 7 \mathrm{R} / \mathrm{NLRP} 3$ pathway, downregulating the expression of Bax and caspase-3, and reducing apoptosis, thereby alleviating kidney injury in mice with ADR nephropathy. Therefore, P2X7R antagonists may potentially be used in the treatment of NS, but more specific studies are required.

Since the initial changes of ADR nephropathy are similar to minimal change type nephropathy, the changes in the model were only observed for 1 week in animal experiments, therefore only the index data for diagnosing NS was recorded in the laboratory at that time. In the future, changes and effects of P2X7R in ADR nephropathy should be further investigated and all relevant biochemical indicators should be evaluated.

\section{Acknowledgements}

Not applicable.

\section{Funding}

The present study was supported by Teachers' research of Jining Medical University (grant no. JYFC2018FKJ042).

\section{Availability of data and materials}

The datasets used and/or analyzed during the current study are available from the corresponding author on reasonable request.

\section{Authors' contributions}

$\mathrm{YZ}$ designed the research. $\mathrm{YZ}$ and $\mathrm{XN}$ performed the experiments. YZ and XN analyzed the data. XN drafted the manuscript and analyzed data. ML, WX and KL collected and interpreted data, and revised the final manuscript. YZ wrote the manuscript. YZ and XN confirm the authenticity of all the raw data. All authors read and approved the final manuscript.

\section{Ethics approval and consent to participate}

All experiments were performed with the approval of the Animal Ethics Committee of Shandong Provincial Hospital (Jinan, China; approval no. 2020-107)

Patient consent for publication 
Not applicable.

\section{Competing interests}

The authors declare that they have no competing interests.

\section{References}

1. Hao S, Wu Y, Kang Y, Niu X, Zhu G and Huang W: A single-center analysis of primary nephrotic syndrome with acute pancreatitis in children. Medicine (Baltimore) 99: e21056, 2020.

2. Chen A, Sheu LF, Ho YS, Lin YF, Chou WY, Chou TC and Lee WH: Experimental focal segmental glomerulosclerosis in mice. Nephron 78: 440-452, 1998.

3. Manabe N, Kinoshita A, Yamaguchi M, Furuya Y, Nagano N, Yamada-Uchio K, Akashi N, Miyamoto-Kuramitsu K and Miyamoto H: Changes in quantitative profile of extracellular matrix components in the kidneys of rats with adriamycin-induced nephropathy. J Vet Med Sci 63: 125-133, 2001.

4. Lydia A, Asanuma K, Nonaka K, Takagi M, Jeong KH, Kodama F, Asao R, Asanuma E, Prodjosudjadi W and Tomino Y: Effects of 22-oxa-calcitriol on podocyte injury in adriamycin-induced nephrosis. Am J Nephrol 35: 58-68, 2012.

5. Wang YM, Wang Y, Harris DCH, Alexander SI and Lee VWS: Adriamycin nephropathy in BALB/c mice. Curr Protoc Immunol 108: 15.28.1-15.28.6, 2015.

6. Adinolfi E, Giuliani AL, De Marchi E, Pegoraro A, Orioli E and Di Virgilio F: The P2X7 receptor: A main player in inflammation. Biochem Pharmacol 151: 234-244, 2018.

7. Jiang LH, Baldwin JM, Roger S and Baldwin SA: Insights into the molecular mechanisms underlying mammalian $\mathrm{P} 2 \mathrm{X} 7$ receptor functions and contributions in diseases, revealed by structural modeling and single nucleotide polymorphisms. Front Pharmacol 4: 55, 2013.

8. Arkhipov SN and Pavlov TS: ATP release into ADPKD cysts via pannexin-1/P2X7 channels decreases ENaC activity. Biochem Biophys Res Commun 513: 166-171, 2019.

9. Wang C, Hou XX, Rui HL, Li LJ, Zhao J, Yang M, Sun LJ, Dong HR, Cheng $\mathrm{H}$ and Chen YP: Artificially cultivated ophiocordyceps sinensis alleviates diabetic nephropathy and its podocyte injury via inhibiting P2X7R expression and NLRP3 inflammasome activation. J Diabetes Res 2018: 1390418, 2018.

10. Franco M, Bautista-Pérez R, Cano-Martínez A, Pacheco U, Santamaría J, Del Valle Mondragón L, Pérez-Méndez O and Navar LG: Physiopathological implications of P2X1 and P2X7 receptors in regulation of glomerular hemodynamics in angiotensin II-induced hypertension. Am J Physiol Renal Physiol 313 : F9-F19, 2017.

11. Koo TY, Lee JG, Yan JJ, Jang JY, Ju KD, Han M, Oh KH, Ahn C and Yang J: The P2X7 receptor antagonist, oxidized adenosine triphosphate, ameliorates renal ischemia-reperfusion injury by expansion of regulatory T cells. Kidney Int 92: 415-431, 2017.

12. Harada H, Chan CM, Loesch A, Unwin R and Burnstock G: Induction of proliferation and apoptotic cell death via P2Y and $\mathrm{P} 2 \mathrm{X}$ receptors, respectively, in rat glomerular mesangial cells. Kidney Int 57: 949-958, 2000.

13. Sha W, Shen L, Zhou L, Xu DY and Lu GY: Down-regulation of miR-186 contributes to podocytes apoptosis in membranous nephropathy. Biomed Pharmacother 75: 179-184, 2015.

14. Beaucage KL, Xiao A, Pollmann SI, Grol MW, Beach RJ, Holdsworth DW, Sims SM, Darling MR and Dixon SJ: Loss of P2X7 nucleotide receptor function leads to abnormal fat distribution in mice. Purinergic Signal 10: 291-304, 2014.

15. Peng K, Liu L, Wei D, Lv Y, Wang G, Xiong W, Wang X, Altaf A, Wang L, He D, et al: P2X7R is involved in the progression of atherosclerosis by promoting NLRP3 inflammasome activation. Int J Mol Med 35: 1179-1188, 2015.

16. Wang C, Li Q, Zhen J, Xu Y and Sun S: Simvastatin ameliorates renal lipidosis through the suppression of renal CXCL16 expression in mice with adriamycin-induced nephropathy. Int J Clin Exp Pathol 8: 15696-15707, 2015.
17. Gauckler P, Shin JI, Alberici F, Audard V, Bruchfeld A, Busch M, Cheung CK, Crnogorac M, Delbarba E, Eller K, et al: Rituximab in adult minimal change disease and focal segmental glomerulosclerosis-what is known and what is still unknown? Autoimmun Rev 19: 102671, 2020.

18. Gentile D, Natale M, Lazzerini PE, Capecchi PL and Laghi-Pasini F: The role of P2X7 receptors in tissue fibrosis: A brief review. Purinergic Signal 11: 435-440, 2015.

19. Vonend O, Turner CM, Chan CM, Loesch A, Dell'Anna GC, Srai KS, Burnstock G and Unwin RJ: Glomerular expression of the ATP-sensitive $\mathrm{P} 2 \mathrm{X}$ receptor in diabetic and hypertensive rat models. Kidney Int 66: 157-166, 2004.

20. Mansouri E, Assarehzadegan MA, Nejad-Dehbashi F and Kooti W: Effects of Pravastatin in adriamycin-induced nephropathy in rats. Iran J Pharm Res 17: 1413-1419, 2018.

21. Lee VW and Harris DC: Adriamycin nephropathy: A model of focal segmental glomerulosclerosis. Nephrology (Carlton) 16: 30-38, 2011.

22. Lee HS: Oxidized LDL, glomerular mesangial cells and collagen. Diabetes Res Clin Pract 45: 117-122, 1999.

23. Korhonen M, Ylänne J, Laitinen L and Virtanen I: The alpha 1-alpha 6 subunits of integrins are characteristically expressed in distinct segments of developing and adult human nephron. J Cell Biol 111: 1245-1254, 1990.

24. Lee HS, Jeong JY, Kim BC, Kim YS, Zhang YZ and Chung HK: Dietary antioxidant inhibits lipoprotein oxidation and renal injury in experimental focal segmental glomerulosclerosis. Kidney Int 51; 1151-1159, 1997.

25. Zhang G, Li Q, Wang L, Chen Y, Zhang W and Yang H: The effects of inflammation on lipid accumulation in the kidneys of children with primary nephrotic syndrome. Inflammation 34 : 645-652, 2011.

26. Moorhead JF, Chan MK, El-Nahas M and Varghese Z: Lipid nephrotoxicity in chronic progressive glomerular and tubulo-interstitial disease. Lancet 2: 1309-1311, 1982.

27. Vaziri ND, Navab M and Fogelman AM: HDL metabolism and activity in chronic kidney disease. Nat Rev Nephrol 6: 287-296, 2010.

28. Hu ZB, Chen Y, Gong YX, Gao M, Zhang Y, Wang GH, Tang RN, Liu H, Liu BC and Ma KL: Activation of the CXCL16/CXCR6 pathway by inflammation contributes to atherosclerosis in patients with end-stage renal disease. Int J Med Sci 13: 858-867, 2016.

29. Di Virgilio F: The therapeutic potential of modifying inflammasomes and NOD-like receptors. Pharmacol Rev 65: 872-905, 2013.

30. Ogura Y, Sutterwala FS and Flavell RA: The inflammasome: First line of the immune response to cell stress. Cell 126: 659-662, 2006.

31. Turner CM, Tam FW, Lai PC, Tarzi RM, Burnstock G, Pusey CD Cook HT and Unwin RJ: Increased expression of the pro-apoptotic ATP-sensitive P2X7 receptor in experimental and human glomerulonephritis. Nephrol Dial Transplant 22: 386-395, 2007.

32. Eamshaw WC, Martins LM and Kaufinann SH: Mammalian caspases: Structure, activation, substrates, and functions during apoptosis. Annu Rev Biochem 68: 383-424, 1999.

33. Zhang Y, Yuan F, Cao X, Zhai Z, Huang G, Du X, Wang Y, Zhang J, Huang Y, Zhao J and Hou W: P2X7 receptor blockade protects against cisplatin-induced nephrotoxicity in mice by decreasing the activities of inflammasome components, oxidative stress and caspase-3. Toxicol Appl Pharmacol 281: 1-10, 2014.

34. Liu L, Yang L, Chang B, Zhang J, Guo Y and Yang X: The protective effects of rapamycin on cell autophagy in the renal tissues of rats with diabetic nephropathy via mTOR-S6K1-LC3II signaling pathway. Ren Fail 40: 492-497, 2018.

This work is licensed under a Creative Commons Attribution-NonCommercial-NoDerivatives 4.0 International (CC BY-NC-ND 4.0) License. 